\title{
Effect of Ultrasonic Treatment Combined with Peracetic Acid Treatment Reduces Decay and Maintains Quality in Loquat Fruit
}

\author{
Chen Ling, Jia Xu, Shuang Shao, Li Wang, Peng Jin (D), and Yonghua Zheng \\ College of Food Science and Technology, Nanjing Agricultural University, Nanjing 210095, China \\ Correspondence should be addressed to Peng Jin; pjin@njau.edu.cn
}

Received 18 September 2017; Revised 18 December 2017; Accepted 9 January 2018; Published 8 February 2018

Academic Editor: Jorge Barros-Velázquez

Copyright ( 2018 Chen Ling et al. This is an open access article distributed under the Creative Commons Attribution License, which permits unrestricted use, distribution, and reproduction in any medium, provided the original work is properly cited.

\begin{abstract}
The effects of ultrasonic treatment (UT, 400 watts for $6 \mathrm{~min})$ combined with peracetic acid (PA, $0.4 \%(\mathrm{~W} / \mathrm{W})$ ) treatment on fruit decay, browning, and quality and physiological changes in loquat fruit stored at $20^{\circ} \mathrm{C}$ were investigated. The results showed that treatment with UT or PA alone significantly reduced both decay and browning index in loquat fruit compared with the control. The combined treatment was more effective in decreasing decay and browning index and maintaining higher quality parameters than UT or PA treatment alone. Loquat fruits treated with the combined treatment maintained higher activities of polyphenol oxidase (PPO) and peroxidase (POD) than those treated with other treatments. In addition, UT combined with PA treatment significantly reduced the increase of firmness and increased fruit extractable juice, total soluble solid (TSS), and ascorbic acid content in loquat fruit. Moreover, the contents of total phenolics and total flavonoids were enhanced by the combination of UT and PA treatment. The combination of UT and PA treatment could be a useful method to reduce decay and browning in loquat fruit stored at room temperature, which has potential for application in the loquat industry.
\end{abstract}

\section{Introduction}

Loquat fruit (Eriobotrya japonica Lindl), a famous local fruit of China, is popular for its delicious tastes and good nutrition. However, loquat fruit is highly perishable and susceptible to the attack of fungal and bacterial pathogen during storage at room temperature [1]. In addition, flesh leatheriness is regarded as fruit senescence and physiological deterioration in red-fleshed loquat cultivars during room temperature storage or even refrigeration, which limited its storage period and shelf life. The main symptoms of flesh leatheriness in loquats are related to increase in fruit firmness, dry or hard texture, juiceless pulp, and adhesion of peel to the flesh, which is a major problem during loquat fruit storage [2]. Traditionally, fungicide has been widely applied to prevent postharvest decay of loquat fruit [3]. However, consumers are concerned about potentially harmful effects on the chemical residues, human health, and environment pollution caused by synthetic fungicides [4]. Therefore, it is urgent to develop new methods to control postharvest decay in loquat fruit stored at room temperature.
Ultrasonic treatment (UT) is a useful method and widely applied in extraction of bioactive compounds or food processing industry [5]. More attentions are attracted to the application of ultrasonic technology in food processing and preservation. In recent years, several studies reported that UT was effective in controlling postharvest decay in fruits and vegetables such as strawberry and tomato fruit $[6,7]$. Peracetic acid (PA) is an efficient disinfectant with a wide spectrum of antimicrobial activities and due to its bactericidal, fungicidal, and sporicidal effectiveness within several minutes, the use of PA as a disinfectant for food has been drawing more attention in recent years [8]. PA is safe and efficient since the end product of PA decomposition is $\mathrm{CO}_{2}, \mathrm{H}_{2} \mathrm{O}$, and $\mathrm{O}_{2}$; for example, $15 \mathrm{mg} / \mathrm{L}$ PA disinfection for 1-2 min in French families is a routine disinfection procedure before edible fruits and vegetables [9-11]. At present, PA has been widely used as a new method in medical, drinking water and food processing industry, which suggests that PA is useful in the preservation of fresh-cut vegetables including tomato, lettuce, carrots, and cauliflower [11-14]. Another study also indicated 
that PA treatment was effective in maintaining quality and decreasing the rate of postharvest decay in sweet melon [15].

Recently, there is increasing evidence that the combination of different postharvest treatments usually has better effect on maintaining quality of fresh produce than using a single technique. UT combined with other chemical treatment had synergistic effect in maintaining postharvest quality in some fruits and vegetables. For example, UT combined with chlorine dioxide or citric acid treatment had better effect on prolonging shelf life and retaining nutrients in plum fruit or fresh-cut broccoli $[16,17]$. Some scientists found that PA combined with hot water treatment was good to control postharvest brown rot and maintain the overall quality on peaches, nectarines, and fresh-cut Galia melon [18, 19]. In addition, a study showed that PA combined with calcium treatment obviously reduced the occurrence of decay and kept quality of loquat fruit during storage [9]. However, there is little available study on the combined effects of UT and PA treatment on decay and quality controlling in postharvest loquat fruit. The present study was therefore undertaken to investigate their combined effects on postharvest decay and quality of loquat fruit in postharvest life.

\section{Materials and Methods}

2.1. Fruit Material and Treatment. Loquat fruit (Eriobotrya japonica L. cv. "Jiefangzhong") were hand-harvested at commercial maturity with light orange color from a commercial orchard in Fujian, China. The fruits were transported within $24 \mathrm{~h}$ to our laboratory and selected for uniform size, color, and absence of mechanical damage and insect pests. Loquat fruit were then randomly divided into four groups and subjected to following treatments:

(1) Control (CK): the fruits were immersed into distilled water at $20^{\circ} \mathrm{C}$ for $6 \mathrm{~min}$

(2) Ultrasonic treatment (UT): the fruits were held in an ultrasonic chamber (KQ-500DE, Kunshan Science and Technology Co.) at a constant frequency of $40 \mathrm{kHz}$ by immersion into distilled water at $20^{\circ} \mathrm{C}$ and treated with ultrasonic power of 400 Watt for $6 \mathrm{~min}$

(3) Peracetic acid (PA) treatment: the fruits were immersed into $0.4 \%(\mathrm{~W} / \mathrm{W}) \mathrm{PA}$ solution at $20^{\circ} \mathrm{C}$ for $6 \mathrm{~min}$

(4) Ultrasonic combined with peracetic acid treatment $(\mathrm{UT}+\mathrm{PA})$ : the fruits were treated with ultrasonic power of 400 watts by immersion into $0.4 \%$ (W/W) PA solution at $20^{\circ} \mathrm{C}$ for $6 \mathrm{~min}$.

After treatment, all loquat fruit were air-dried for approximately $30 \mathrm{~min}$ and transferred into a thermostatic container of $20 \pm 1^{\circ} \mathrm{C}$ and about $95 \%$ relative humidity for 12 days. The combined treatment condition (including ultrasonic power, treatment time, and peracetic acid concentration) was optimized by using the response surface methodology (RSM) in our previous study [20]. In the previous study, three secondorder quadratic equations of fruit decay index, browning index, and extractable juice were established and the parameters were analyzed through RSM. The results suggested that the optimum condition of UT combined with PA treatment was a UT power of 400 watts for $6 \mathrm{~min}$ with PA concentration of $0.4 \%(\mathrm{~W} / \mathrm{W})$. Thus, the optimum combined treatment condition was chosen in this study. Each treatment was replicated three times and the experiment was conducted twice. A fifteen-fruit sample, from each treatment from each replicate, was taken every 3 days during storage to evaluate decay and browning index, firmness, extractable juice, and TSS content and then tissue samples were frozen in liquid nitrogen and stored at $-80^{\circ} \mathrm{C}$ until biochemical analysis.

2.2. Measurement of Decay and Browning Index. The decay index was evaluated visually by means of a five-grade scale according to decay area, where 0 indicates no decay area of the fruit surface; 1 indicates decay area $<25 \%$ of the fruit surface; 2 indicates decay area between $25 \%$ and $50 \%$ of the fruit surface; 3 indicates decay area between $50 \%$ and $75 \%$ of the fruit surface; and 4 indicates decay area $>75 \%$ of the fruit surface. The decay index was calculated using the following formula: decay index $=\sum[$ (decay scale $) \times($ number of fruit at that scale $)] /(4 \times$ total number of fruit in each treatment $) \times$ $100 \%$.

The severity of internal browning index was measured according to the method [21] as follows: 0: none; 1: browning area $<5 \%$; 2: browning area 5-25\%; 3: browning area 25-50\%; 4: browning area $>50 \%$. The internal browning index was calculated using the following formula: browning index $=$ $\sum[$ (browning level) $\times$ (number of fruit at that browning) $] /$ $(4 \times$ total number of fruit in each treatment $) \times 100 \%$.

2.3. Determination of Quality Parameters. Fruit firmness was measured using the method of Cao et al. [22]. Ten loquat fruit were assayed on two opposite sides with a TA-XT2i texture analyzer (Stable Micro System Ltd., UK) with a $5 \mathrm{~mm}$ diameter probe at a speed of $1 \mathrm{mms}^{-1}$. The extractable juice was determined by measuring the weight loss from tissue disks ( $6 \mathrm{~mm}$ in diameter and $10 \mathrm{~mm}$ in thickness) after centrifuging for $10 \mathrm{~min}$ at the speed of $1500 \times \mathrm{g}$ at room temperature. The result was expressed as \% fresh weight loss of the tissue plugs after centrifugation. The total soluble solid (TSS) content was measured at $20^{\circ} \mathrm{C}$ by using a portable refractometer (PAL-1, Tokyo, Japan) and the result was expressed as a percentage. The ascorbic acid content was measured according to the method of Zhang et al. [23]. The reaction mixture was monitored at the absorbance of $534 \mathrm{~nm}$. The result was expressed as mg per $\mathrm{kg}$ of fresh weight (FW).

2.4. Evaluation of Total Phenolics and Total Flavonoids. The total phenolics content was determined according to the Folin-Ciocalteu procedure [24]. Two grams of flesh tissue was ground in $5.0 \mathrm{~mL}$ of $80 \%(\mathrm{v} / \mathrm{v})$ cold acetone and then the mixture was centrifuged at $12000 \times \mathrm{g}$ for $20 \mathrm{~min}$ at $4^{\circ} \mathrm{C}$. The supernatant was used for the total phenolics measurement. The reaction mixture was allowed to react at $30^{\circ} \mathrm{C}$ for 1 hour. The control blank was done in the same way but the distilled water was used to calculate the total phenolics content. The result was expressed as gram of gallic acid equivalent (GAE) per $100 \mathrm{~g}$ of fresh weight (FW). The total flavonoids content was measured by the method of Toor and Savage [25]. The reaction mixture consisted of $2.0 \mathrm{~mL}$ extraction, $2.0 \mathrm{~mL}$ of $3 \%$ (w/v) $\mathrm{AlCl}_{3}$, and $1.0 \mathrm{~mL}$ of $70 \%(\mathrm{v} / \mathrm{v})$ ethanol. The standard 


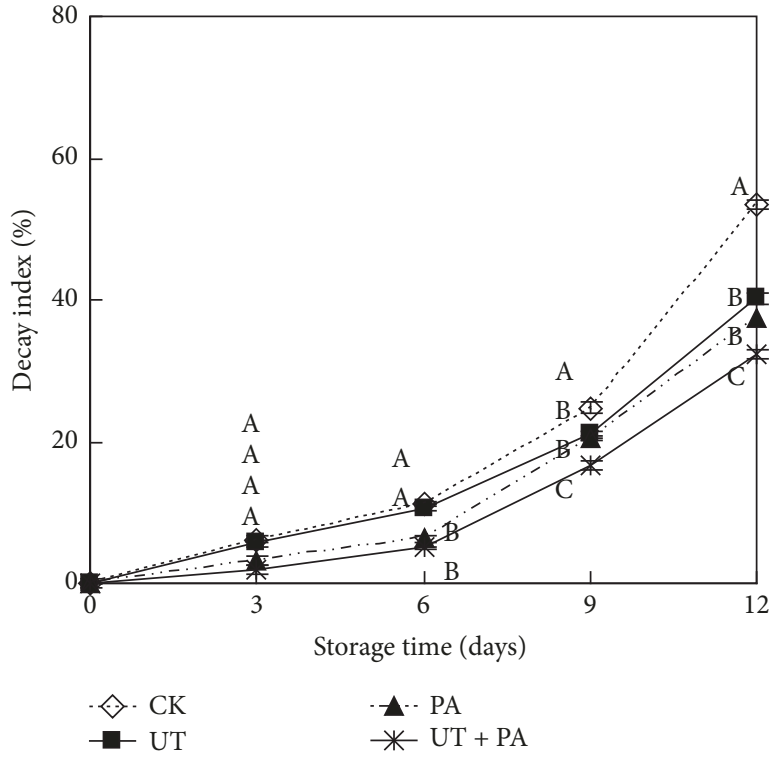

(a)

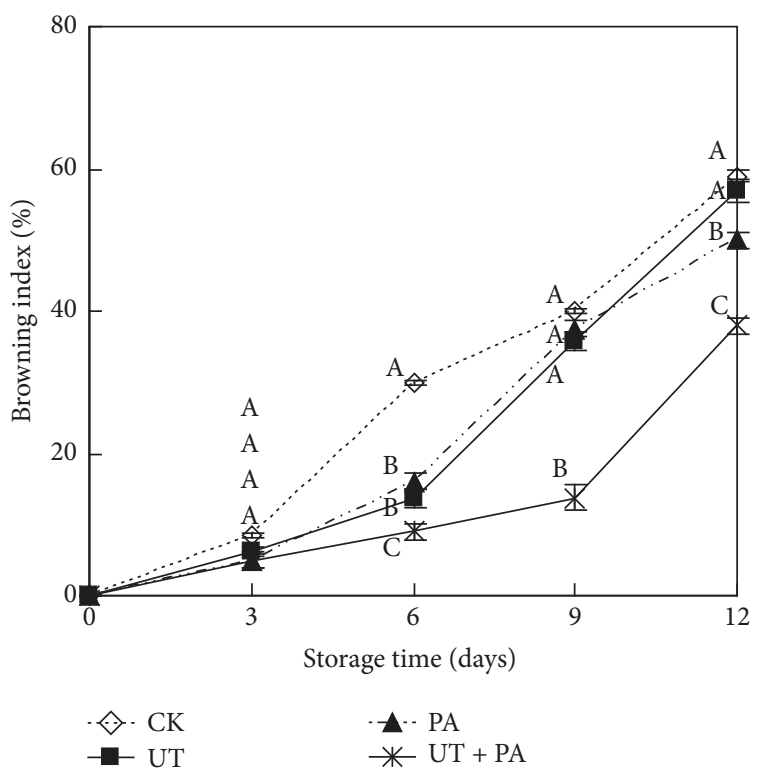

(b)

Figure 1: Effect of UT combined with PA treatment on decay index (a) and browning index (b) in loquat fruit during storage. Data are expressed as mean of triplicate samples \pm standard errors. Vertical bars represent the standard errors of the means. Significant differences $(P<0.05)$ are shown by different letters.

solution was made up of $5 \mathrm{mg}$ of rutin (Sigma), and 70\% ethanol was added to make a volume of $10.0 \mathrm{~mL}$. The total flavonoids content was expressed as $\mathrm{mg}$ rutin equivalents (RE) per $100 \mathrm{~g}$ of fresh weight (FW).

2.5. Measurement of $P P O$ and $P O D$ Activities. All enzyme extraction procedures were conducted at $4^{\circ} \mathrm{C}$. For PPO, the frozen tissue $(2 \mathrm{~g})$ was ground with $5.0 \mathrm{~mL}$ of $0.2 \mathrm{M}$ sodium phosphate buffer $(\mathrm{pH} 6.5)$ containing $1 \%(\mathrm{w} / \mathrm{v})$ polyvinylpyrrolidone (PVP), or with $50 \mathrm{mM}$ sodium phosphate buffer ( $\mathrm{pH}$ 8.7) for POD. The extracts were then homogenized and centrifuged at $12000 \times \mathrm{g}$ for $20 \mathrm{~min}$ at $4^{\circ} \mathrm{C}$. The supernatants were used for the enzyme assays.

PPO activity was assayed by adopting the method described by Jin et al. [26]. Each $3.0 \mathrm{~mL}$ of assay medium contained $0.1 \mathrm{~mL}$ supernatant, $0.1 \mathrm{M}$ catechol, and $0.1 \mathrm{M}$ sodium phosphate buffer ( $\mathrm{pH}$ 6.5). One unit of PPO activity was defined as the amount of enzyme causing an increase of 0.01 in absorbance per minute at $420 \mathrm{~nm}$.

POD activity was assayed using guaiacol as a donor and $\mathrm{H}_{2} \mathrm{O}_{2}$ as a substrate [27]. The reaction mixture consisted of $0.1 \mathrm{~mL}$ supernatant, $0.3 \%(\mathrm{w} / \mathrm{v})$ guaiacol, $0.1 \mathrm{M}$ potassium phosphate buffer ( $\mathrm{pH} 8.7)$, and $0.75 \%(\mathrm{v} / \mathrm{v}) \mathrm{H}_{2} \mathrm{O}_{2}$. One unit of POD activity was defined as an increase of 0.001 in absorbance per minute at $470 \mathrm{~nm}$.

Protein content in the enzyme extracts was estimated using the Bradford method [28], using bovine serum albumin as a standard. Specific activity of the enzymes was expressed as units per milligram of protein.

2.6. Statistical Analysis. Experiments were performed using a completely randomized design. The data presented were expressed as the means \pm SE (standard error) of triplicate assays. All statistical analyses were performed with SPSS 14.0 (SPSS Inc., Chicago, IL, USA). The data were performed by using Duncan's multiple range tests. Differences at $P<0.05$ were considered to be significant.

\section{Results}

3.1. Effect of UT Combined with PA Treatment on Decay and Browning Index in Loquat Fruit. As shown in Figure 1, the decay index and browning index of loquat fruit increased gradually with storage time. In general, PA and the combined treatment prevent the increase of decay index in loquat fruit during the storage time. No significant differences were found between control and UT alone before day 6 . All treatments had the lower decay index than the control on days 9 and 12, and the combination treatment had the best effect, which was significantly $(P<0.05)$ lower than control. At the end of the storage, the decay index of loquat fruit in the combination treatment was only $32.3 \%$, which was $39.5 \%$ lower than that in control.

The browning index of all fruits exhibited a marked increase after day 3 during storage at room temperature. In all treatments, the browning index was significantly $(P<0.05)$ decreased compared with control on day 6 . In general, UT combined with PA treatment significantly $(P<0.05)$ prevented the browning index compared with control and UT or PA treatment alone after day 3. No significant difference was found in browning index between UT and PA treatment alone before day 9. At the end of the storage, the browning index in the combination treatment was only $37.9 \%$, which was $35.8 \%$ lower than that in control. 


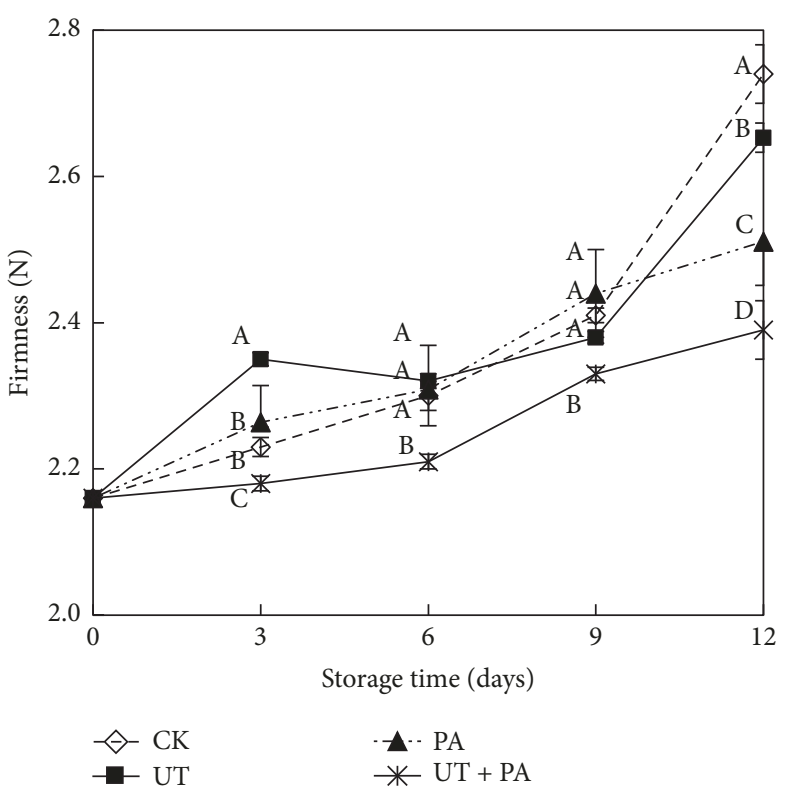

(a)

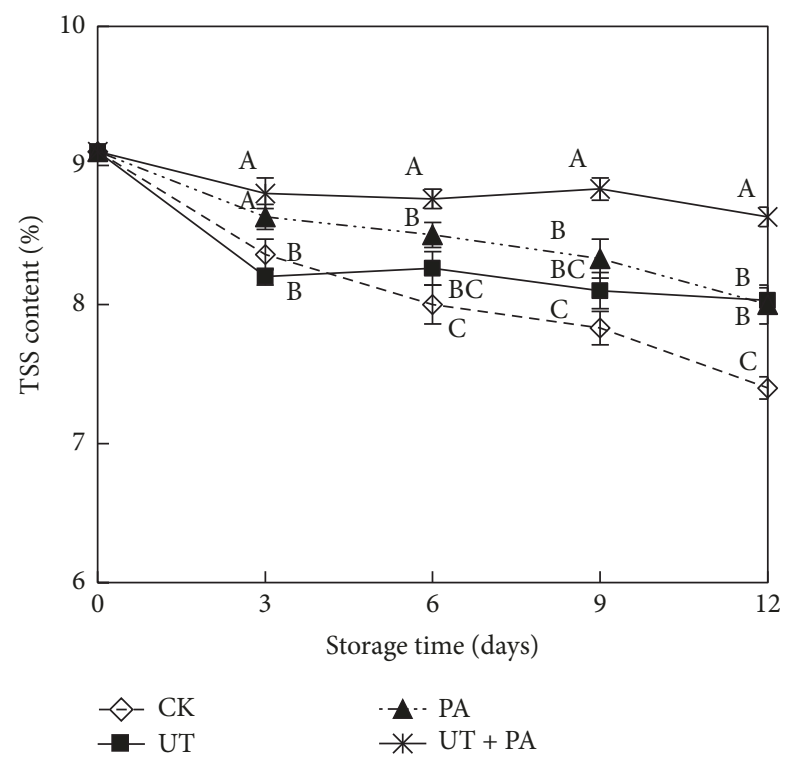

(c)

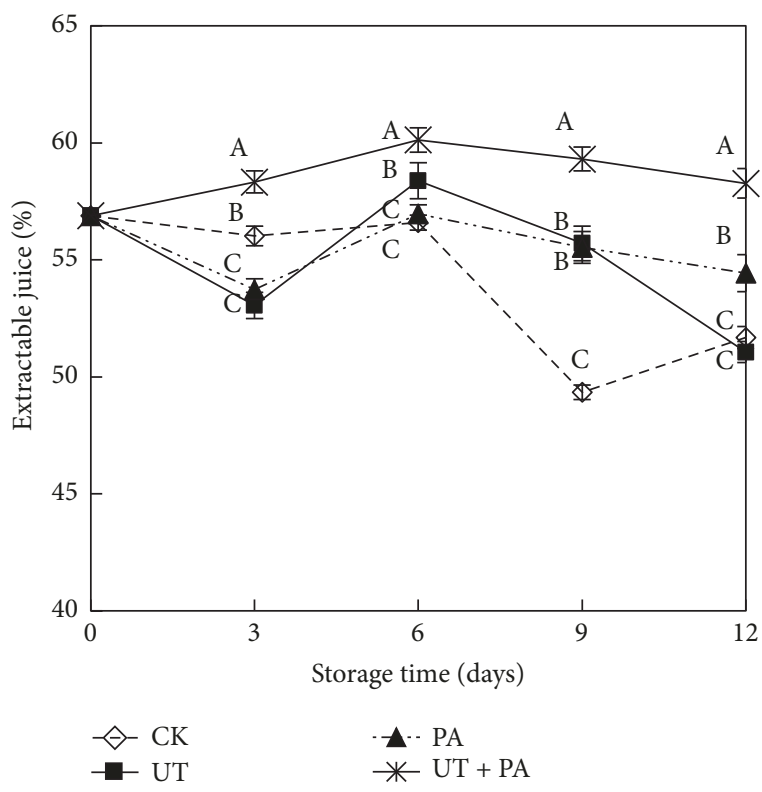

(b)

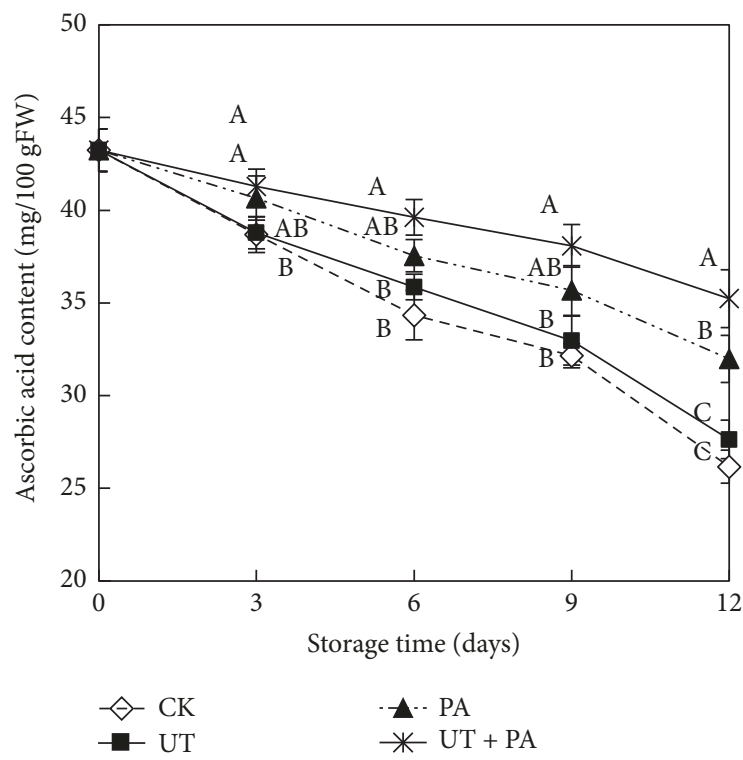

(d)

FIGURE 2: Effect of UT combined with PA treatment on firmness (a), extractable juice (b), TSS content (c), and ascorbic acid content (d) in loquat fruit during storage. Data are expressed as mean of triplicate samples \pm standard errors. Vertical bars represent the standard errors of the means. Significant differences $(P<0.05)$ are shown by different letters.

\subsection{Effect of UT Combined with PA Treatment on Quality} Parameters in Loquat Fruit. Fruit firmness, extractable juice, TSS, and ascorbic acid content were assayed to evaluate the quality of loquat fruit during storage at room temperature. As shown in Figure 2, firmness increased gradually with storage time, while extractable juice, TSS, and ascorbic acid content decreased. The firmness in control loquat was increased rapidly after day 6, stored at room temperature (Figure 2(a)). No significant differences were found between UT and PA treatments in changes of fruit firmness on days 6 and 9, but the firmness in PA treatment was much lower than that in
UT alone on day 12. The combined treatment with UT and PA significantly $(P<0.05)$ prevented the increase of fruit firmness during the storage compared to control and UT or PA treatment alone.

In general, the combination treatment kept significant $(P<0.05)$ high level of extractable juice in comparison to control and UT or PA treatment alone during storage time. There was no significant difference between UT and PA treatment alone. At the end of storage, the extractable juice in the combination treatment was $12.8 \%$ higher than that in control (Figure 2(b)). As to TSS content, UT or PA treatment alone 


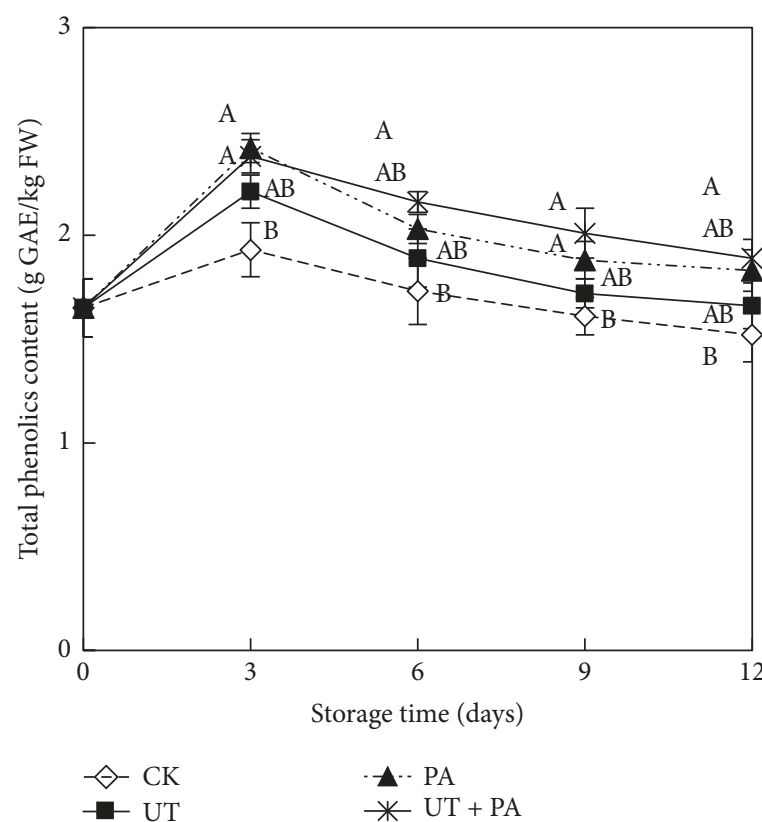

(a)

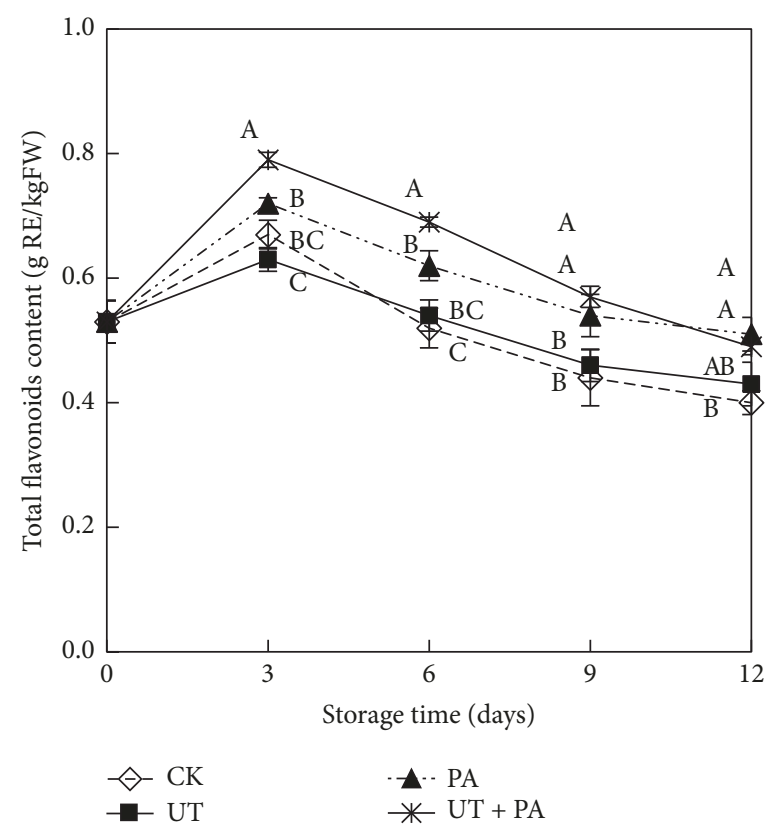

(b)

Figure 3: Effect of UT combined with PA treatment on total phenolics content (a) and total flavonoids (b) content. Data are expressed as mean of triplicate samples \pm standard errors. Vertical bars represent the standard errors of the means. Significant differences $(P<0.05)$ are shown by different letters.

was effective in retarding the decrease after day 6 (Figure 2(c)). The combined treatment maintained a highest level in comparison to other treatments during storage time. A higher content of ascorbic acid was found in loquat fruit treated with PA compared to that in UT or control (Figure $2(\mathrm{~d}))$. The combination treatment had the significantly $(P<0.05)$ higher content of ascorbic acid than control during the whole storage time. However, UT alone had similar changes to control. The content of ascorbic acid in the combination treatment was $34.62 \%$ higher than that in control at the end of the storage.

\subsection{Effect of UT Combined with PA Treatment on Total Phe-} nolics and Flavonoids in Loquat Fruit. As shown in Figure 3, total phenolics and total flavonoids content were increased slightly before day 3 and decreased afterwards. In general, all treatments enhanced the level of the total phenolics content during the storage and the combination treatment had the best effect. The content of total phenolic was significantly $(P<$ 0.05 ) higher in the combination treatment than that in control during the whole storage time.

The total flavonoids content in loquat fruits increased to maximum values on day 3 and decreased afterwards. The PA and the combined treatment maintained the higher level of total flavonoids than control and UT alone, whereas the combined treatment had better effect before day 9. No significant differences were found between control and UT in the changes of total flavonoids content during the whole storage time. POD Activities in Loquat Fruit. As shown in Figure 4(a), PPO activity decreased gradually with the storage time. In general, all treatments prevented the decrease and maintained the higher activity of PPO compared with the control during the storage time. UT and the combined treatment induced PPO activity before day 3 . The activity of PPO was much higher in PA and combined treatment than that in control and UT alone after day 6 .

POD activity increased slightly before day 6 and decreased afterwards (Figure 4(b)). PA and the combined treatment significantly $(P<0.05)$ enhanced the activity of POD in loquat fruit during storage time. The combined treatment resulted in a higher induction of POD activity than that in PA treatment alone on days 6 and 9. However, the change of POD activity in UT was similar to control.

\section{Discussion}

In recent years, many researches have paid attention to the effect of the combination treatment on controlling postharvest decay and maintaining quality of fruits and vegetables, and most results showed better effects than a single treatment and control. Similar to the previous reports, our present study found that UT and PA treatment was effective in inhibiting decay index and maintaining quality in loquat fruit. Moreover, our results demonstrated that UT combined with PA treatment was more effective in reducing decay or browning index and prolonging the shelf life of loquat fruit compared with treatment alone. This indicated that UT and PA treatment had synergistic effect that prevented the fruit decay. The combination treatment condition of UT and PA in our study (including ultrasonic power, treatment time, 


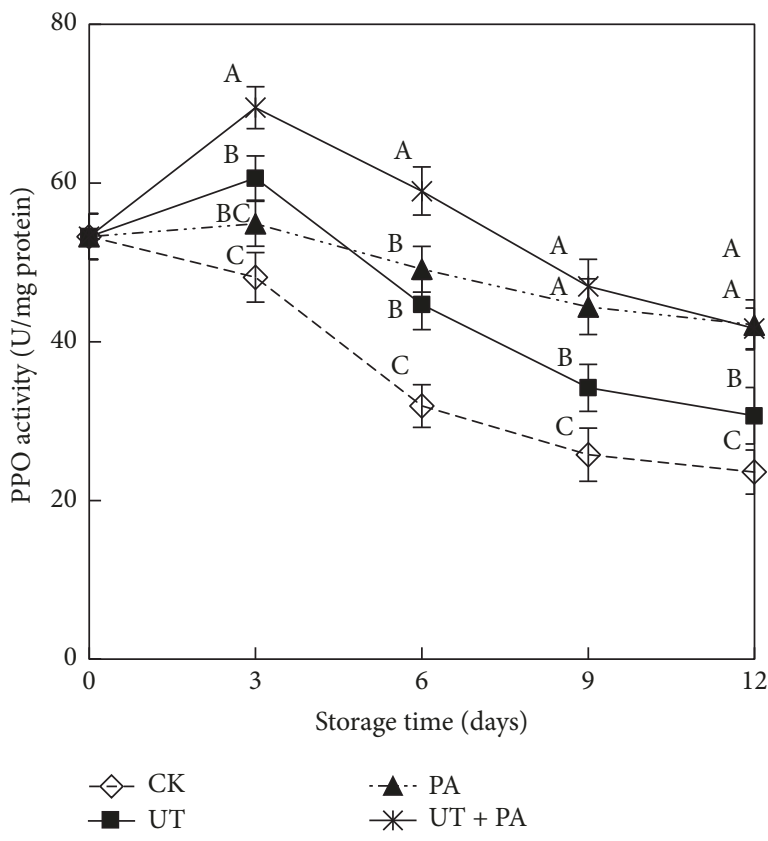

(a)

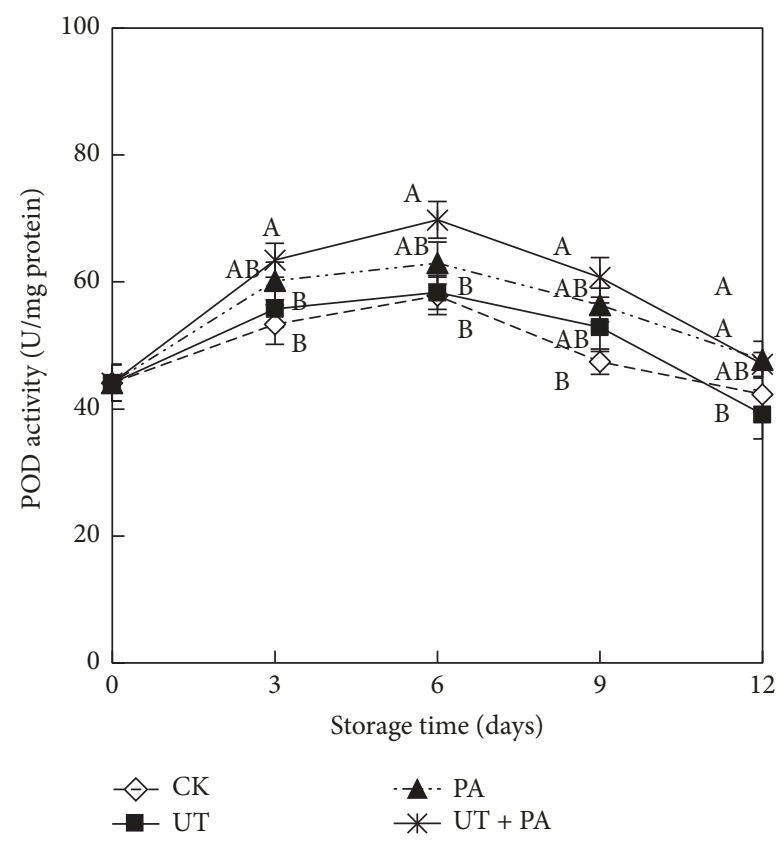

(b)

FIGURE 4: Effect of UT combined with PA treatment on PPO (a) and POD (b) activities in loquat fruit during storage. Data are expressed as mean of triplicate samples \pm standard errors. Vertical bars represent the standard errors of the means. Significant differences $(P<0.05)$ are shown by different letters.

and peracetic acid concentration) was optimized by using the response surface methodology (RSM) in our previous study (data not shown), indicating that ultrasonic power, treatment time, and peracetic acid concentration were crucial factors affecting postharvest decay and quality of loquat fruit. Previous studies had suggested that the combination treatment applied in postharvest fruits was more effective in maintaining quality than treatment alone. A similar result was found where electrolyzed oxidizing (EO) water combined with an ultrasonic wave treatment was more effective in reducing decay compared with treatment alone in pineapple fruit [29]. The effects of aqueous chlorine dioxide combined with ultrasonic treatment on maintaining total flavonoids and ascorbic acid content were more beneficial than a single treatment and control in plum fruit [16]. Liu et al. also suggested that hot air treatment in combination with Pichia guilliermondii reduced decay in loquat fruit [3]. In the present study, we found that fruit treated with UT combined with PA had higher level of the extractable juice, TSS, and ascorbic acid content than UT or PA treatment alone and control. As to the postharvest technique, the combined treatment can shorten treatment time and can be easily used in automatic production line; it could be a useful technique to reduce the incidence of decay and browning and maintain quality in loquat fruit during storage at room temperature.

Some scientists found that the oxalic acid treatment combined with modified atmosphere packaging had good effect on inhibiting the increase of fruit firmness and maintaining total soluble solids (TSS), total phenolics, and total flavonoids content in loquat fruit [30]. This study demonstrated that UT combined with PA treatment had better effect on controlling the incidence of decay and browning and maintaining quality in loquat fruit than the treatment of UT or PA alone, which suggested that the combination treatment activated more defensive capacity against rot in loquat fruit. Since the combination treatment is good for shortening processing time, UT combined with PA treatment has potential value for application in the loquat fruit industry.

The loquat fruit is rich in natural antioxidants such as polyphenols and flavonoids, and these profiles in loquat fruit vary among cultivars [31]. Total phenolics and total flavonoids contents tended to decrease with time storage and the combination treatment kept higher level of total phenolics and total flavonoids contents than those of treatment alone and the control. Our results showed that the application of PA treatment alone resulted in a significant increase in the activities of PPO and POD compared with control and UT alone, which was related to the enhanced disease resistance of loquat fruit. PPO and POD are important enzymes involved in both of phenylpropanoid pathway and oxidation process, a secondary plant metabolism that produces a variety of phenolics with structural and defense-related functions [32, 33]. Accumulated studies found that phenolics compounds in loquat fruit played an important role in disease resistance $[34,35]$. Therefore, our results indicated that UT combined with PA treatment probably had benefit in enhancing disease resistance in loquat fruit throughout inducing the activities of PPO and POD. The increased activities of defense enzymes might be one part of the mechanism of the combined treatment that had better effect than single treatment. 


\section{Conclusions}

In conclusion, the results presented in our study showed that UT combined with PA treatment was more effective in controlling postharvest decay or browning index and maintaining quality in loquat fruit stored at room temperature. The effect of the combined treatment on reducing postharvest decay might be attributed to the induction of disease resistance. At the same time, the combined treatment had no side effect on fruit quality. The results indicated that UT combined with PA treatment could be a reliable treatment method to control postharvest decay and maintain quality of loquat fruit.

\section{Conflicts of Interest}

The authors declare no conflicts of interest.

\section{Acknowledgments}

This study was supported by the National Key Research and Development Program of China (2016YFD0400901) and the Project Funded by the Priority Academic Program Development of Jiangsu Higher Education Institutions.

\section{References}

[1] W. Chen, L. Y. Shi, X. G. Su, and Z. F. Yang, "Research on postharvest quality in loquat fruit of different varieties during low temperature storage," Journal of Food Safety and Quality, 2013.

[2] S. F. Cao and Y. H. Zheng, "Postharvest biology and handling of loquat fruit," Stewart Postharvest Review, vol. 4, no. 2, article no. 3, 2008 .

[3] F. J. Liu, K. Tu, X. F. Shao et al., "Effect of hot air treatment in combination with Pichia guilliermondii on postharvest anthracnose rot of loquat fruit," Postharvest Biology and Technology, vol. 58, no. 1, pp. 65-71, 2010.

[4] H. J. Yao and S. P. Tian, "Effects of a biocontrol agent and methyl jasmonate on postharvest diseases of peach fruit and the possible mechanisms involved," Journal of Applied Microbiology, vol. 98, no. 4, pp. 941-950, 2005.

[5] S. Rodrigues, G. A. S. Pinto, and F. A. N. Fernandes, "Optimization of ultrasound extraction of phenolic compounds from coconut (Cocos nucifera) shell powder by response surface methodology," Ultrasonics Sonochemistry, vol. 15, no. 1, pp. 95-100, 2008.

[6] S. Cao, Z. Hu, B. Pang, H. Wang, H. Xie, and F. Wu, "Effect of ultrasound treatment on fruit decay and quality maintenance in strawberry after harvest," Food Control, vol. 21, no. 4, pp. 529532,2010

[7] J. Pinheiro, C. Alegria, M. Abreu, E. M. Gonçalves, and C. L. M. Silva, "Influence of postharvest ultrasounds treatments on tomato (Solanum lycopersicum, cv. Zinac) quality and microbial load during storage," Ultrasonics Sonochemistry, vol. 27, pp. 552-559, 2015.

[8] M. Kitis, "Disinfection of wastewater with peracetic acid: a review," Environment International, vol. 30, no. 1, pp. 47-55, 2004.

[9] H. Gao, H. Chen, L. Song, J. Mao, Y. Jiang, and Y. Zheng, "Effects of short-term $\mathrm{n} 2$ treatment on quality of loquat fruit during cold storage," Acta Horticulturae, no. 877, pp. 899-903, 2010.
[10] W. Shen and R. Y. Zhu, "Research progress of peracetic acid and hydrogen peroxide disinfectant," Chinese Journal of Disinfection, vol. 27, no. 4, pp. 456-457, 2010 (Chinese).

[11] H. Kim, J.-H. Ryu, and L. R. Beuchat, "Survival of Enterobacter sakazakii on fresh produce as affected by temperature, and effectiveness of sanitizers for its elimination," International Journal of Food Microbiology, vol. 111, no. 2, pp. 134-143, 2006.

[12] A. Martínez-Sánchez, A. Allende, R. N. Bennett, F. Ferreres, and M. I. Gil, "Microbial, nutritional and sensory quality of rocket leaves as affected by different sanitizers," Postharvest Biology and Technology, vol. 42, no. 1, pp. 86-97, 2006.

[13] A. Allende, M. V. Selma, F. López-Gálvez, R. Villaescusa, and M. I. Gil, "Role of commercial sanitizers and washing systems on epiphytic microorganisms and sensory quality of fresh-cut escarole and lettuce," Postharvest Biology and Technology, vol. 49, no. 1, pp. 155-163, 2008.

[14] I. Vandekinderen, F. Devlieghere, B. De Meulenaer, P. Ragaert, and J. Van Camp, "Optimization and evaluation of a decontamination step with peroxyacetic acid for fresh-cut produce," Food Microbiology, vol. 26, no. 8, pp. 882-888, 2009.

[15] X. M. Zhang, Y. Q. Bai, X. X. Ma, and J. Xu, "Effect of peroxyacetic acid on post-harvest physiology of Hamimelon," China Cucurbits and Vegetables, vol. 30, no. 1, pp. 35-38, 2017 (Chinese).

[16] Z. Chen and C. Zhu, "Combined effects of aqueous chlorine dioxide and ultrasonic treatments on postharvest storage quality of plum fruit (Prunus salicina L.)," Postharvest Biology and Technology, vol. 61, no. 2-3, pp. 117-123, 2011.

[17] M. R. Ansorena, M. R. Moreira, and S. I. Roura, "Combined effect of ultrasound, mild heat shock and citric acid to retain greenness, nutritional and microbiological quality of minimally processed broccoli (Brassica oleracea L.): An optimization study," Postharvest Biology and Technology, vol. 94, pp. 1-13, 2014.

[18] M. Sisquella, C. Casals, I. Viñas, N. Teixidó, and J. Usall, “Combination of peracetic acid and hot water treatment to control postharvest brown rot on peaches and nectarines," Postharvest Biology and Technology, vol. 83, pp. 1-8, 2013.

[19] A. C. Silveira, E. Aguayo, V. H. Escalona, and F. Artés, "Hot water treatment and peracetic acid to maintain fresh-cut Galia melon quality," Innovative Food Science and Emerging Technologies, vol. 12, no. 4, pp. 569-576, 2011.

[20] J. Xu, Study on effect of ultrasonic treatment combined with peracetic acid on decay and quality of loquat fruit during ambient temperature storage (Master Thesis [Master, thesis], Nanjing Agricultural University, Nanjing, Jiangsu, China, 2015.

[21] C. Cai, C. Xu, L. Shan et al., "Low temperature conditioning reduces postharvest chilling injury in loquat fruit," Postharvest Biology and Technology, vol. 41, no. 3, pp. 252-259, 2006.

[22] S. Cao, Y. Zheng, K. Wang, P. Jin, and H. Rui, "Methyl jasmonate reduces chilling injury and enhances antioxidant enzyme activity in postharvest loquat fruit," Food Chemistry, vol. 115, no. 4, pp. 1458-1463, 2009.

[23] Y. Zhang, P. Jin, Y. Huang et al., "Effect of hot water combined with glycine betaine alleviates chilling injury in cold-stored loquat fruit," Postharvest Biology and Technology, vol. 118, pp. 141-147, 2016.

[24] H. Gao, Z. Zhang, X. Lv, N. Cheng, B. Peng, and W. Cao, "Effect of 24-epibrassinolide on chilling injury of peach fruit in relation to phenolic and proline metabolisms," Postharvest Biology and Technology, vol. 111, pp. 390-397, 2016. 
[25] R. K. Toor and G. P. Savage, "Antioxidant activity in different fractions of tomatoes," Food Research International, vol. 38, no. 5, pp. 487-494, 2005.

[26] P. Jin, Y. Duan, L. Wang, J. Wang, and Y. Zheng, "Reducing Chilling Injury of Loquat Fruit by Combined Treatment with Hot Air and Methyl Jasmonate," Food and Bioprocess Technology, vol. 7, no. 8, pp. 2259-2266, 2014.

[27] H. Gao, Z. Lu, Y. Yang et al., "Melatonin treatment reduces chilling injury in peach fruit through its regulation of membrane fatty acid contents and phenolic metabolism," Food Chemistry, vol. 245, pp. 659-666, 2018.

[28] M. M. Bradford, "A rapid and sensitive method for the quantitation of microgram quantities of protein utilizing the principle of protein dye binding," Analytical Biochemistry, vol. 72, no. 1-2, pp. 248-254, 1976.

[29] S. Khayankarn, J. Uthaibutra, S. Setha, and K. Whangchai, "Using electrolyzed oxidizing water combined with an ultrasonic wave on the postharvest diseases control of pineapple fruit cv. 'Phu Lae,' Crop Protection, vol. 54, pp. 43-47, 2013.

[30] A. T. Öz, E. Kafkas, and A. Bozdoğan, "Combined effects of oxalic acid treatment and modified atmosphere packaging on postharvest quality of loquats during storage," Turkish Journal of Agriculture and Forestry, vol. 40, no. 3, pp. 433-440, 2016.

[31] M. Petriccione, M. S. Pasquariello, F. Mastrobuoni, L. Zampella, D. Di Patre, and M. Scortichini, "Influence of a chitosan coating on the quality and nutraceutical traits of loquat fruit during postharvest life," Scientia Horticulturae, vol. 197, pp. 287-296, 2015.

[32] Y. Lin, J. Z. Sun, and Y. H. Chen, "Inhibition of postharvest disease and induction of defense-related enzymes by paper containing 1-Methylcyclopropene (1-MPC) in Averrhoa carambola fruit," Chinese Journal of Tropical Crops, vol. 37, no. 6, pp. 11721176, 2016.

[33] Y. Wang, Y. Zhang, Y. Luo, and D. Fu, "Effect of blue mould rot on the quality and resistance systems of apple," Journal of Chinese Institute of Food Science and Technology, vol. 16, no. 8, pp. 166-171, 2016.

[34] Y. X. Zhang, A. S. Zeng, L. X. Song, B. Gao, and J. Y. Yan, "Study on the phenolics to resistant black rot in cabbage," Journal of Yangzhou University (Agricultural and Life Science Edition, vol. 36, no. 1, pp. 92-96, 2015.

[35] Y. P. Tang, Y. L. Shi, J. H. He, L. J. Ma, and H. L. Zhou, "Phenolic metabolism of apple fruit with different grey mold disease resistance," Acta Botanica Boreali-Occidentalia Sinica, vol. 37, no. 3, pp. 510-516, 2017. 


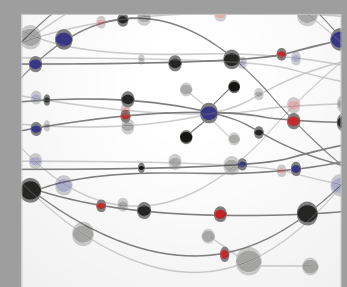

The Scientific World Journal
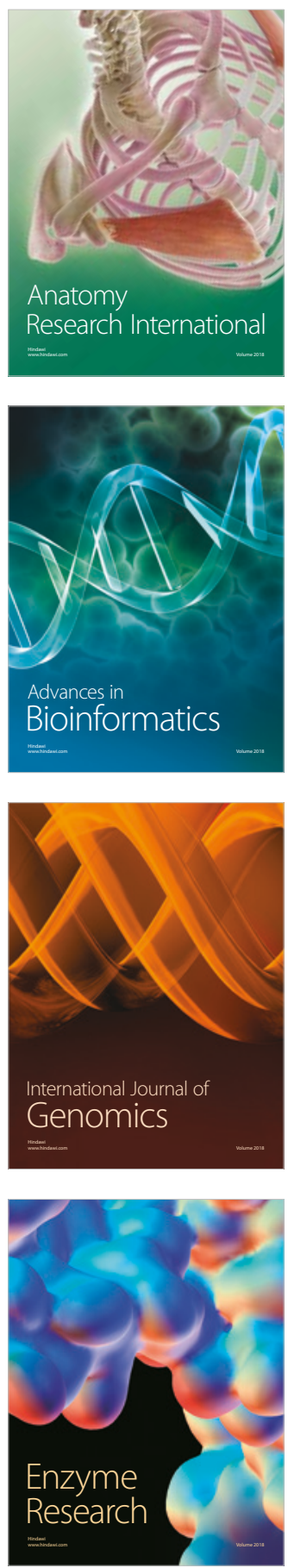
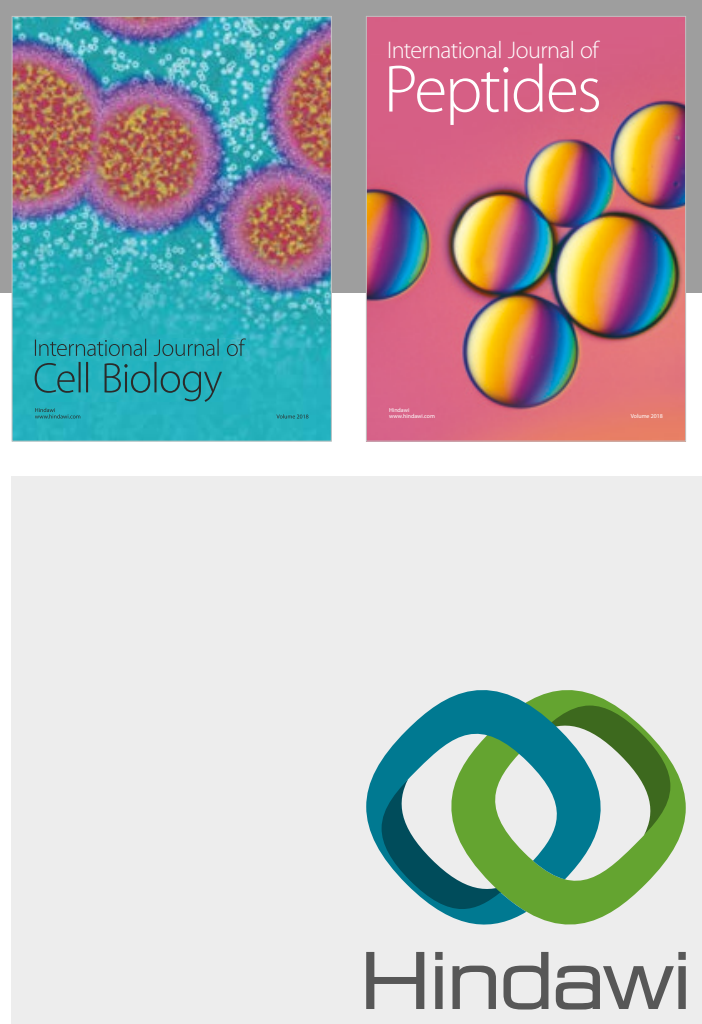

Submit your manuscripts at

www.hindawi.com
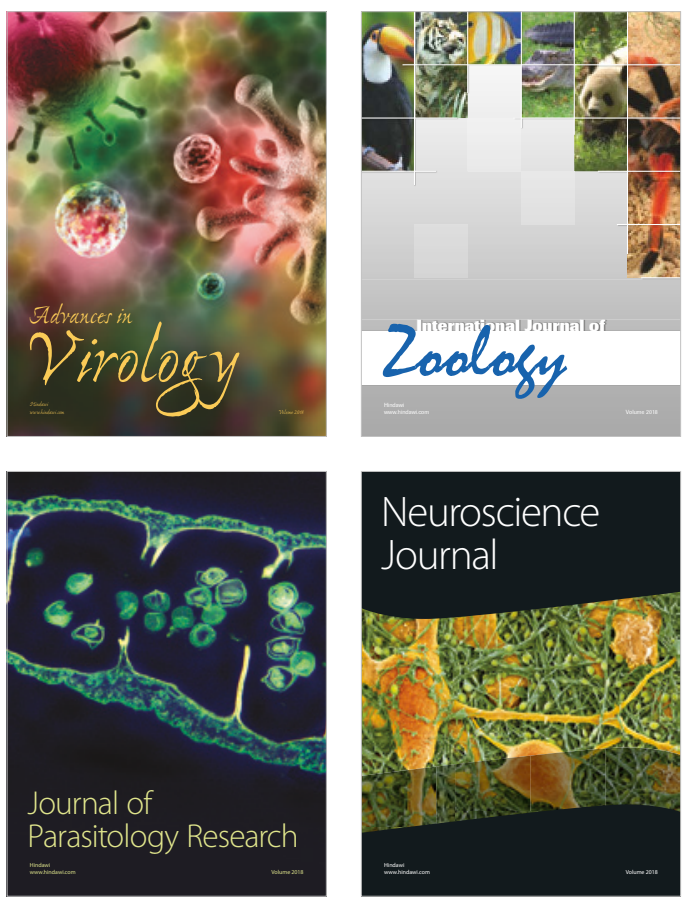
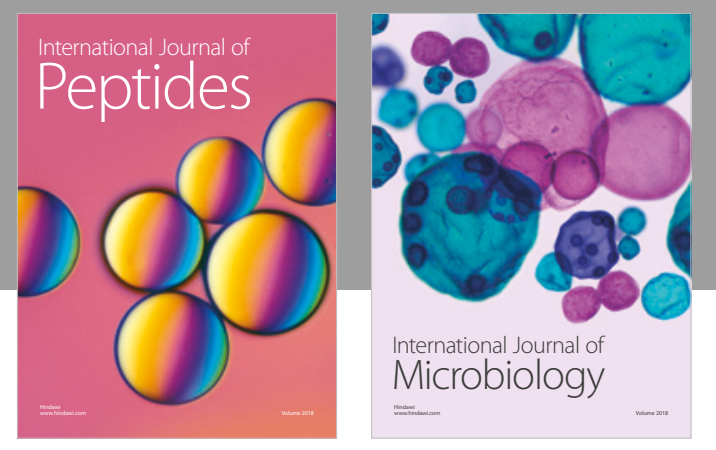

nternational Journal of Microbiology
Journal of
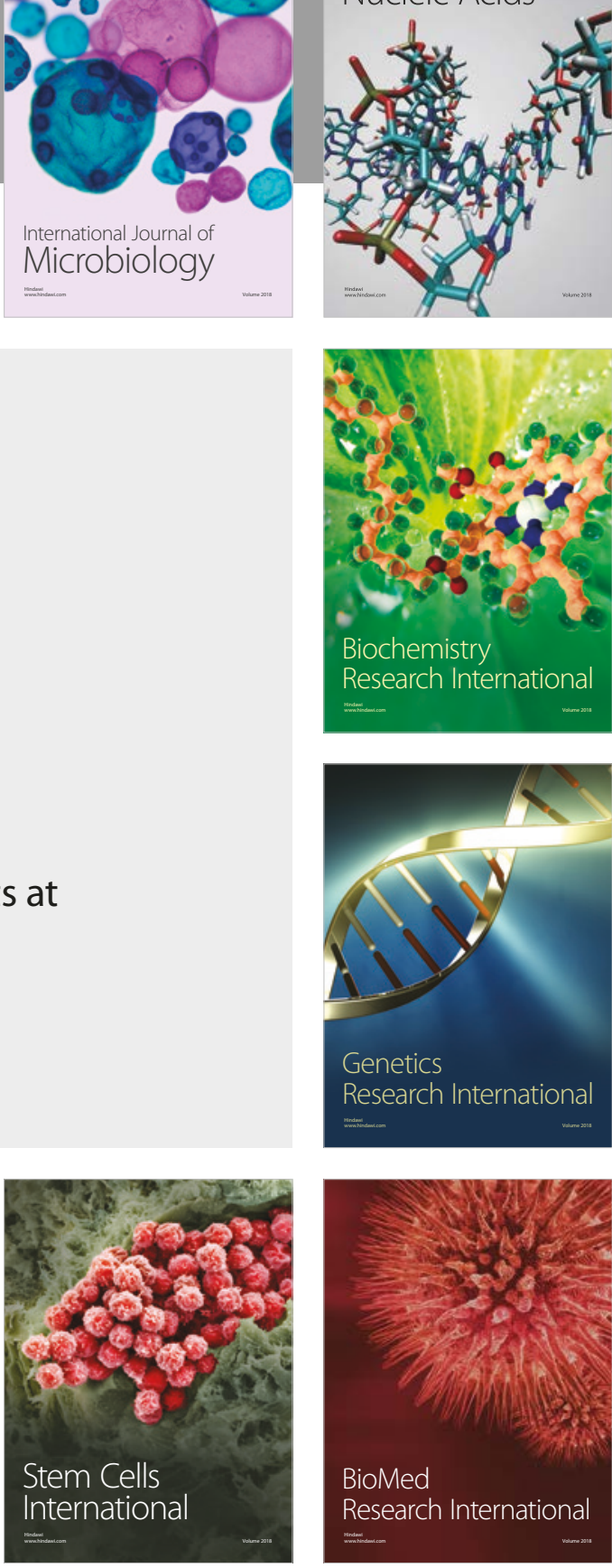
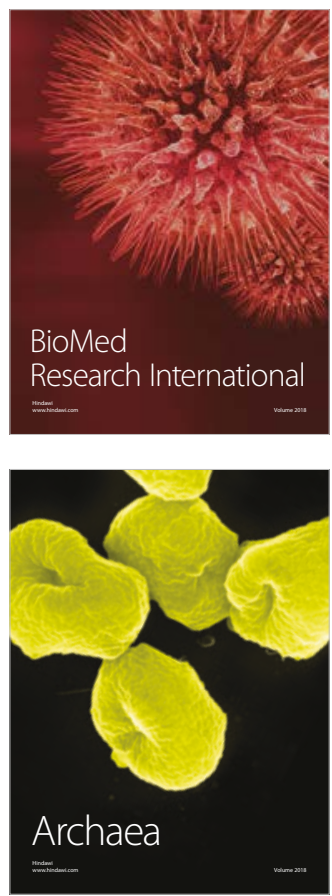